Pesq. Vet. Bras. 36(1):1-12, janeiro 2016

DOI: $10.1590 / \mathrm{S} 0100-736 \mathrm{X} 2016000100001$

\title{
Avaliação clínica, laboratorial e anatomopatológica do sistema urinário de ovinos confinados com ou sem suplementação de cloreto de amônio ${ }^{1}$
}

\author{
Bianca P. Santarosa2*, Danilo O.L. Ferreira ${ }^{3}$, Marcela M.P. Rodrigues ${ }^{2}$, Gabriela N. Dantas², \\ Soraya R. Sacco ${ }^{2}$, Raimundo Souza Lopes ${ }^{2}$, Adriano Dias ${ }^{4}$ e Roberto C. Gonçalves ${ }^{2}$
}

\begin{abstract}
Santarosa B.P., Ferreira D.O.L., Rodrigues M.M.P., Dantas G.N., Sacco S.R., Lopes R.S., Dias A. \& Gonçalves R.C. 2016. [Clinical, laboratory and anatomopathological evaluation of the urinary system of feedlot sheep with or without ammonium chloride supplementation.] Avaliação clínica, laboratorial e anatomopatológica do sistema urinário de ovinos confinados com ou sem suplementação de cloreto de amônio. Pesquisa Veterinária Brasileira 36(1):1-12. Departamento de Clínica Veterinária, Faculdade de Medicina Veterinária e Zootecnia, Universidade Estadual Paulista, Campus de Botucatu. Distrito de Rubião Júnior s/n, Botucatu, SP 18618-970, Brazil. E-mail: biancasantarosavet@gmail.com

The urinary acidification with ammonium chloride (AC) is an efficient preventive method for urolithiasis in sheep. The objectives of this study with feedlot sheep receiving concentrated diet with high protein content were (1) to verify the effect of diet on urolith formation and development of the disease, (2) to analyze the macroscopic and histopathological characteristics of the urinary system, and (3) to relate the clinical, laboratory and necropsy findings with the presence of uroliths. Sixty male sheep were used: AC group $(\mathrm{n}=40), 400 \mathrm{mg} / \mathrm{kg} \mathrm{AC} /$ day, orally treated for 42 consecutive days, and control group $(\mathrm{n}=20)$, untreated. Seven times were determined for sampling with a seven-day interval, totaling 56 days of feedlot. Small uroliths were found in the renal pelvis of five sheep in both groups. The most relevant microscopic renal lesions were vascular congestion and tubular necrosis. It was concluded that the highly concentrated diet caused renal injury in both groups, without changing the renal function, what was proven by laboratory tests of urea and creatinine. Ammonium chloride provided to the CA group did not prevent urolith formation, but reduced its prevalence in comparison with the control group. Sheep of the control group had increased kidney damage, which resulted in higher incidence of crystalluria and tubular necrosis induced by the consumption of a diet rich in grains.
\end{abstract}

INDEX TERMS: Histopatholgy, kidneys, small ruminants, urinary acidifiers, urolithiasis.

\footnotetext{
${ }^{1}$ Recebido em 11 de junho de 2015.

Aceito para publicação em 13 de outubro de 2015.

Dissertação de mestrado da primeira autora. Bolsa de mestrado (Proc. 2012/24985-4) da Fundação de Amparo à Pesquisa do Estado de São Paulo (FAPESP).

${ }^{2}$ Departamento de Clínica Veterinária, Faculdade de Medicina Veterinária e Zootecnia (FMVZ), Universidade Estadual Paulista (Unesp), Campus de Botucatu, Distrito de Rubião Júnior s/n, Botucatu, SP 18618-970, Brasil. *Autora para correspondência: biancasantarosavet@gmail.com

${ }^{3}$ Secretaria da Agricultura e Abastecimento do estado de São Paulo, Coordenadoria de Assistência Técnica Integral, Casa da Agricultura de Agudos, Rua Odom Pessoa de Albuquerque 788, Centro. Agudos, SP 17120000, Brasil.

${ }^{4}$ Departamento de Saúde Pública, Faculdade de Medicina de Botucatu (FMB), Universidade Estadual Paulista (Unesp), Campus de Botucatu, Distrito de Rubião Júnior s/n, Botucatu, SP 18618-970.
}

RESUMO.- A acidificação urinária com cloreto de amônio (CA) é um método preventivo eficiente em urolitíase obstrutiva em ovinos. Os objetivos deste estudo com ovinos confinados, que receberam dieta concentrada com elevado teor proteico, foram: verificar o efeito da dieta sobre a formação de urólitos e o desenvolvimento da doença; analisar as características macroscópicas e histopatológicas do sistema urinário; relacionar os achados clínicos, laboratoriais e necroscópicos com a presença de urólitos. Utilizaram-se 60 ovinos machos: grupo CA $(\mathrm{n}=40), 400 \mathrm{mg} / \mathrm{kg} \mathrm{CA} / \mathrm{dia}$, tratados via oral, por 42 dias consecutivos; grupo-controle $(\mathrm{n}=20)$, não tratado. Determinaram-se sete momentos de colheita de amostras com intervalos de sete dias, no total de 56 dias de confinamento. Encontraram-se microcálculos 
na pelve renal em cinco animais de ambos os grupos. As lesões renais microscópicas mais relevantes foram congestão vascular e necrose tubular. Concluiu-se que a dieta rica em concentrado provocou lesão renal em ambos os grupos, embora sem alterar a função renal, o que foi comprovado em testes pela ureia e creatinina séricas. 0 cloreto de amônio fornecido ao grupo CA não impediu a calculogênese, mas reduziu sua prevalência em relação ao grupo-controle. Os ovinos do grupo-controle tiveram maior comprometimento renal, pela alta incidência de cristalúria e pela necrose tubular, induzidas pelo consumo da dieta rica em grãos.

TERMOS DE INDEXAÇÃO: Acidificante urinário, histopatologia, pequenos ruminantes, rins, urolitíase.

\section{INTRODUÇÃO}

A intensificação da produção, aliada à comercialização de animais de alto valor genético, acarretou profundas alterações no manejo alimentar dos ovinos, desencadeando o aumento da ocorrência de doenças nutricionais e metabólicas, entre as quais se destaca a urolitíase (Riet-Correa et al. 2008, Kannan \& Lawrence 2010). Considerada como enfermidade de maior importância do trato urinário de ruminantes, a urolitíase afeta particularmente machos e causa sérios prejuízos econômicos relacionados à saída prematura dos animais da reprodução, gastos com tratamento, morte dos animais afetados e condenação da carcaça em abate emergencial (Antonelli et al. 2012, Guimarães et al. 2012).

Os melhores resultados são obtidos com a prevenção da doença, antes que se inicie a formação do cálculo, com vista à integridade produtiva do animal (Van Metre \& Fubini 2006, Ewoldt et al. 2008, Kinsley et al. 2013). Para isso, deve-se conhecer a composição química dos urólitos e corrigir todos os possíveis fatores que podem estar relacionados com sua formação (Freeman et al. 2010, Sun et al. 2010). Entre os métodos de prevenção, a acidificação urinária com cloreto de amônio (CA) é uma alternativa eficiente (Stewart et al. 1991, Mavangira et al. 2010, Ferreira et al. 2014a). Pode-se utilizá-lo na dieta total, à proporção de $0,5 \%$ a $1 \%$, ou $2 \%$ do concentrado (Stratton-Phelps \& House 2004), ou em doses individuais de 5 a 10g/animal/dia (Navarre 2007). Mavangira et al. (2010) obtiveram pH urinário menor do que $6,5 \mathrm{em}$ caprinos, com a dose de $450 \mathrm{mg} / \mathrm{kg} / \mathrm{PV}$ de CA /dia, ou 2,25\% da ingestão de matéria seca (MS). Ferreira et al. (2014a) atingiram o pH urinário de 6,1 em ovinos, e a acidez foi mantida enquanto houve administração do CA, fornecido a $400 \mathrm{mg} / \mathrm{kg} / \mathrm{PV} /$ dia junto com a dieta total.

Na literatura, a vitamina C (ácido ascórbico) também é classificada como acidificante urinário satisfatório quando administrada à dose de $3 \mathrm{a} 4 \mathrm{mg} / \mathrm{kg} /$ dia (Belknap \& Pugh 2005, Navarre 2007). Ferreira et al. (2011) estudaram o efeito da administração de CA e vitamina C sobre a acidificação urinária em ovinos e mostraram que ambos os produtos apresentaram resultados na acidificação, porém, foi notória a eficácia com que o $\mathrm{CA}$ diminuiu o $\mathrm{pH}$ da urina, mantendo a acidificação até o final do experimento, ao contrário do ácido ascórbico que não estabilizou o pH da urina abaixo de sete.
Embora a acidificação urinária seja um método preventivo e eficaz para diminuir a incidência da urolitíase obstrutiva, a alimentação rica em grãos pode provocar lesões inflamatórias no trato urinário que, pelo aumento de proteínas e restos celulares na urina, facilitam a formação do núcleo dos urólitos (Ferreira et al. 2014a). Em animais confinados e destinados ao abate para comercialização da carne, muitas vezes não se notam sinais clínicos da urolitíase, pois o tempo para a terminação do animal é curto, porém, em estudos anteriores demonstrou-se a possibilidade de a dieta rica em proteína ocasionar lesão renal e formação de cálculos (Ferreira 2009, 2013).

Diante da relevância dessa enfermidade para a ovinocultura, os objetivos deste estudo com ovinos confinados, que receberam dieta concentrada com elevado teor proteico, suplementados ou não com CA, foram: verificar o efeito da dieta fornecida no confinamento, rica em concentrado, sobre a formação de urólitos e desenvolvimento de urolitíase obstrutiva; analisar as características macroscópicas e histopatológicas do sistema urinário; relacionar os achados clínicos, os exames laboratoriais de função renal (ureia e creatinina séricas, e urinálise) e necroscópicos com a presença de urólitos.

\section{MATERIAL E MÉTODOS}

A metodologia adotada durante o desenvolvimento deste trabalho foi aprovada pela Comissão de Ética no Uso de Animais (CEUA), da Faculdade de Medicina Veterinária e Zootecnia (FMVZ) da Universidade Estadual Paulista (Unesp), Botucatu, SP (Protocolo 240/2012).

Utilizaram-se 60 ovinos machos, não castrados, hígidos, mestiços das raças Ile de France $\mathrm{x}$ White Dorper, de três meses de idade, com peso médio inicial de $22 \mathrm{~kg}$, distribuídos em dois grupos. Antes do início do experimento, todos os animais receberam vermífugo (Cydectin ${ }^{\circledR} 1 \%$ injetável, Fort Dodge, Campinas/SP, Brasil) e vacina contra clostridiose (Sintoxan Polivalente ${ }^{\circledR}$, Merial, Campinas/SP, Brasil). Depois disso, foram adaptados ao ambiente, por 14 dias, alocados em baias coletivas de 4,0 $\mathrm{m}$ x 3,0m localizadas no Hospital Veterinário da FMVZ/Unesp-Botucatu. Todos os animais estiveram no mesmo ambiente em condições iguais de temperatura, umidade do ar e luminosidade. 0 piso de cimento da baia era revestido com maravalha, que era trocada semanalmente, após lavagem e higienização com solução de amônia quaternária.

A alimentação consistiu de ração total composta por $85 \%$ de ração comercial balanceada para terminação de cordeiros (milho, soja e trigo) e $15 \%$ de feno triturado de capim-coast-cross (cultivar de Cynodon dactylon), fornecida em 0,6 m de cocho/animal. Forneceu-se sal mineral (Ovinofós com Monensina ${ }^{\circledR}$, Tortuga Companhia Zootécnica Agrária, Mairinque/SP, Brasil), em cocho separado, e água ad libitum. A água era proveniente da SABESP (Companhia de Saneamento Básico do Estado de São Paulo) e era colocada manualmente duas vezes ao dia, em cocho de plástico de $100 \mathrm{~L}$.

A ração total foi fornecida à vontade, de forma farelada, para favorecer a mistura e homogeneização com o CA, que era adicionado à alimentação no cocho. Para o cálculo do volume de CA, estabeleceu-se peso médio, a partir de pesagem semanal em balança, para o lote de animais de cada baia do grupo CA, tendo-se utilizado a dose de $400 \mathrm{mg} / \mathrm{kg} / \mathrm{PV}$. Pela manhã, para garantir o consumo adequado de CA, limpava-se o cocho para retirar as sobras do dia anterior e se fornecia pequena quantidade de ração total com a dose de CA para todos os cordeiros. Aguardava-se, 
portanto, o tempo necessário para que os animais ingerissem a ração suplementada com CA e, somente depois disso, era adicionada ração à vontade.

Para a segurança experimental, a ração total foi submetida à análise bromatológica, que foi caracterizada pelos seguintes níveis em matéria seca (MS): 20,34\% de proteína bruta, 2,37\% de extrato etéreo, $6,12 \%$ de fibra bruta e $4,41 \%$ de minerais. Realizou-se, também, a análise dos minerais da ração total utilizada no experimento, cujas dosagens de cálcio e fósforo foram de $4130 \mathrm{ppm}$ e $5515 \mathrm{ppm}$ de MS, respectivamente, o que resultou proporção Ca:P de 1:1,33. 0 consumo médio diário foi de $3 \%$ do peso vivo de MS, com média de $1,2 \mathrm{~kg}$ de ração total durante o período experimental.

Iniciado o experimento, os animais foram identificados com colares cervicais, numerados e distribuídos de forma aleatória para a constituição dos grupos, e permaneceram nas respectivas baias por 56 dias, quando continuaram recebendo a mesma dieta do período de adaptação. 0 período experimental compreendeu o tempo usual de confinamento de cordeiros para abate, que foram desmamados aos 60 a 80 dias de idade, com média de peso de 22 $\mathrm{kg}$, e confinados por 60 dias, para que atingissem o peso médio final de 35 a $40 \mathrm{~kg}$ de peso vivo aos 150 dias de vida (Pires et al. 2000, Prado et al. 2013).

Constituíram-se dois grupos experimentais: grupo CA $(n=40)$, que recebeu $400 \mathrm{mg} / \mathrm{kg} / \mathrm{PV}$ de CA/animal/dia, por 42 dias consecutivos; grupo-controle $(\mathrm{n}=20)$, que não recebeu CA. Os momentos (M) de colheita de amostras e a avaliação clínica foram realizados com intervalo de sete dias, em que: M0 é o momento imediatamente antes do início do tratamento com CA; M1, sete dias; M2, 14 dias após; M3, 21 dias após; M4, 28 dias após; M5, 35 dias após; e M6, 42 dias após o tratamento, no total de 56 dias de confinamento.

Todas as colheitas de urina e sangue foram realizadas antes do fornecimento da alimentação, entre $6 \mathrm{~h}$ e $8 \mathrm{~h}$. Os ovinos foram contidos em estação, manualmente, com o uso de cabresto. Colheram-se amostras de urina dos animais dos dois grupos por micção natural ou forçada pela interrupção da respiração por oclusão das narinas de 10 a 20 segundos (Garcia-Navarro 2005).

As amostras de urina foram acondicionadas em frascos estéreis e, em seguida, encaminhadas ao Serviço de Patologia Clínica, do Departamento de Clínica Veterinária da FMVZ/Unesp-Botucatu. A urinálise foi realizada imediatamente após a colheita de urina de cada animal.

No exame físico foram avaliados volume (mL), cor, odor e aspecto, de maneira subjetiva. A densidade foi analisada por refratômetro (Atago ${ }^{\circledR}$ T2, NE Clinical, Atago Brasil Ltda., Ribeirão Preto/SP, Brasil). O exame químico foi realizado por tiras reagentes (Combur ${ }^{10}$ Test $^{\circledR}$, Roche Diagnóstica Brasil Ltda., São Paulo/SP, Brasil), tendo-se avaliado $\mathrm{pH}$, proteínas (mg/dL), glicose (mg/dL), acetona, urobilinogênio, bilirrubina, sangue oculto e sais biliares. Mensurou-se o pH pelo peagômetro portátil (pH100 PHTEK ${ }^{\circledR}$ Labmais Comércio de Equipamentos Ltda., Curitiba/PR, Brasil), que foi calibrado a cada dia de exame e a cada cinco animais em solução tampão de pH 4,0 e de pH 7,0. 0 eletrodo do peagômetro foi totalmente imerso dentro da amostra de urina, até a estabilização e foi colocado, na próxima amostra, somente depois de lavado com água destilada e seco com papel absorvente.

Para exame do sedimento urinário, foram centrifugados (Excelsa II ${ }^{\circledR}$, Fanen, São Paulo/SP, Brasil) $5 \mathrm{~mL}$ de urina, em tubos cônicos, a $700 \mathrm{~g}$ por $5 \mathrm{~min}$ (Kaneko et al. 2008). Após a centrifugação, desprezou-se o sobrenadante, tendo-se deixado $0,5 \mathrm{~mL}$ de urina para a realização do exame do sedimento, que incluiu a identificação de células de descamação do trato urinário (células renais, da pelve, vesicais e uretrais), células prostáticas, hemácias e leucócitos.
As células foram quantificadas numericamente por campo, com intervalo de raras células até incontáveis. Outras estruturas como cilindros, cristais, bactérias, espermatozoides e muco também fizeram parte da análise do sedimento e foram quantificadas em cruzes, com intervalo de raros a três cruzes. 0 critério quantitativo adotado pelo Serviço de Patologia Clínica da FMVZ/ Unesp-Botucatu inclui: raras, contagem média <1 célula/campo; uma cruz (+), 1 a 3 células/campo; duas cruzes (++), 3 a 5 células/campo; três cruzes (+++), >5 células/campo; e campo cheio, números de células incontáveis/campo. Todas essas observações foram realizadas por microscopia ótica comum, com aumento de 400 vezes.

Para o exame bioquímico de ureia e creatinina, colheram-se amostras de sangue da veia jugular, com agulha (BD Vacutainer ${ }^{\circledR}$, BD Medical, Curitiba/PR, Brasil) 30x0,8mm, depositadas em tubos a vácuo, com gel ativador de coágulo e, sem anticoagulante, nos diferentes momentos. As amostras foram centrifugadas (Centrífuga Combate Celm ${ }^{\circledR}$, Cia. Equipadora de Laboratórios Modernos, Barueri, SP, Brasil) a $2.000 \mathrm{~g}$ por $10 \mathrm{~min}$; o soro sanguíneo foi separado, armazenado em tubos de plástico (Eppendorf do Brasil Ltda, São Paulo/SP, Brasil) de $2 \mathrm{~mL}$, e congelado a $-20^{\circ} \mathrm{C}$. As alíquotas foram encaminhadas para análise ao Serviço de Patologia Clínica, do Departamento de Clínica Veterinária da FMVZ/Unesp-Botucatu. As dosagens foram feitas por kits comerciais (Katal ${ }^{\circledR}$ Biotecnológica Ind. Com. Ltda., Belo Horizonte/MG, Brasil) pelos métodos: enzimático-colorimétrico, para a determinação da concentração de ureia, e método cinético-colorimétrico, para creatinina, com leitura em espectrofotômetro (Aparelho SB-190 Celm ${ }^{\circledR}$, Cia. Equipadora de Laboratórios Modernos, Barueri/SP, Brasil).

Após 56 dias de confinamento, período em que receberam a mesma dieta, os animais foram necropsiados. 0 sistema urinário foi colhido para exame macro e microscópico imediatamente após o abate. 0 sistema urinário de cada animal foi analisado quanto às alterações macroscópicas e, posteriormente, fragmentos de cada órgão (rim, ureter, bexiga e uretra peniana) foram colhidos, acondicionados em frascos e fixados em solução de formalina tamponada a 10\%. Após 48 horas, as amostras foram transferidas para novos frascos, que continham álcool etílico $70 \%$. Em seguida, os fragmentos foram incluídos em parafina, em cassetes histológicos, para realização de cortes histológicos de $5 \mu \mathrm{m}$ em micrótomo (RM2255-Leica Biosystems, Leica do Brasil Importação e Comércio Ltda, São Paulo/SP, Brasil), para confecção de lâminas, que foram coradas com hematoxilina e eosina (H.E.), no Serviço de Patologia Veterinária da FMVZ/Unesp-Botucatu. Todas as lâminas foram analisadas em microscópio óptico. As alterações histopatológicas dos rins e da bexiga foram classificadas em ausentes, leves, moderadas e acentuadas, de acordo com Guedes Jr et al. (2012).

Para os dados da urinálise, empregou-se apenas a análise descritiva, exceto para o $\mathrm{pH}$ urinário. Os demais dados foram analisados pelo programa IBM SPSS Statistics, v.21, com nível de significância de $95 \%(\mathrm{p}<0,05)$. As variáveis contínuas, testes de bioquímica sérica (ureia e creatinina) em função da distribuição não paramétrica das respostas, foram testadas entre os dois grupos experimentais (grupo CA e grupo-controle) pelo teste de Mann-Whitney, para identificar diferenças entre os grupos dentro do mesmo momento (M) de colheita. As medianas destas variáveis também foram analisadas pelo teste de Friedman, para identificar se havia alguma diferença ao longo dos sete momentos (M0-M6), dentro de cada grupo. Diferenças estatisticamente significativas foram verificadas pelo teste post-hoc de Dunn. As distribuições das variáveis categóricas, alterações macroscópicas e histopatológicas dos rins e bexiga foram avaliadas pelo teste do qui-quadrado. Diferenças estatísticas entre os grupos foram analisadas pelo teste Z, com correção de Bonferroni. 


\section{RESULTADOS E DISCUSSÃO}

Todos os animais ao início do experimento estavam sadios, alertas, ativos e alimentando-se normalmente, e mantiveram-se neste estado até o término do período experimental. As médias das frequências cardíaca e respiratória, movimentos ruminais e temperatura retal dos animais se mantiveram dentro do padrão de normalidade para a espécie ovina, segundo Feitosa (2014).

Os animais dos grupos experimentais não apresentaram sinais clínicos de disúria, obstrução uretral, nem de ruptura de bexiga. Por isso, não foi necessário instituir tratamento conservativo como a sondagem uretral para a técnica de hidropropulsão retrógada, nem o cirúrgico, como a amputação do apêndice vermiforme, uretrostomia perineal ou cistotomia com colocação de catéter de Foley (Ewoldt et al. 2008).

\section{Urinálise}

Todas as amostras (420/420) apresentaram odor sui generis. Os valores de densidade urinária se mantiveram dentro do padrão de normalidade para ovinos (1.0151.045), nos dois grupos estudados, conforme descrito em Garcia-Navarro (2005) e observado por Antonelli et al. (2012) e Mavangira et al. (2010). Todos os animais apresentaram coloração amarelada, que se refere à normalidade para a espécie (Garcia-Navarro 2005). A avaliação do aspecto que classifica as amostras como límpidas ou turvas não mostrou diferença, em todos os momentos e grupos experimentais (Garcia-Navarro 2005). A turbidez da urina relaciona-se à cristalúria e, ainda, à presença de muco, bactéria, células de descamação e cilindros (Araújo et al. 2009, Taffarel et al. 2012).

No exame químico, não houve sinais de glicosúria, cetonúria, bilirrubinúria em nenhuma amostra dos grupos, nos diferentes momentos (420/420). O urobilinogênio esteve normal em todas as amostras também (420/420), visto que pequena quantidade presente na urina é fisiológica e é principal pigmento que proporciona a cor amarelada à urina (Garcia-Navarro 2005).

O pH urinário (Quadro 1) apresentou variação entre os grupos e momentos, especialmente pelo uso do acidificante urinário no grupo CA, bem como pelo consumo da dieta acidogênica, rica em concentrado. Mesmo antes do início do tratamento do grupo CA e do grupo-controle - que não

\begin{tabular}{|c|c|c|c|c|}
\hline \multirow[t]{2}{*}{ M } & \multicolumn{2}{|c|}{ Grupo CA $(n=40)$} & \multicolumn{2}{|c|}{ Grupo controle $(n=20)$} \\
\hline & $\bar{x} \pm s$ & $M d$ & $\bar{X} \pm S$ & $M d$ \\
\hline M0 & $5,92 \pm 0,95$ & $5,50^{\mathrm{Aa}}$ & $5,95 \pm 0,74$ & $5,62^{\mathrm{Aa}}$ \\
\hline M1 & $6,20 \pm 0,40$ & $6,08^{\mathrm{Aa}}$ & $6,10 \pm 0,29$ & $6,05^{\mathrm{Aa}}$ \\
\hline M2 & $6,00 \pm 0$ & $6,09^{\mathrm{Ba}}$ & $6,90 \pm 1,01$ & $7,30^{\mathrm{Bb}}$ \\
\hline M3 & $5,80 \pm 0$ & $5,79^{\mathrm{Ba}}$ & $6,30 \pm 0,85$ & $6,52^{\mathrm{Ab}}$ \\
\hline M4 & $5,90 \pm 0,40$ & $5,73^{\mathrm{Ba}}$ & $6,40 \pm 0,96$ & $6,03^{\mathrm{Ab}}$ \\
\hline M5 & $6,00 \pm 0,40$ & $5,69^{\mathrm{Ba}}$ & $6,70 \pm 0,79$ & $6,83^{\mathrm{Ab}}$ \\
\hline M6 & $5,70 \pm 0,40$ & $5,77^{\mathrm{Ba}}$ & $6,90 \pm 0,72$ & $6,82^{\mathrm{Ab}}$ \\
\hline
\end{tabular}

$\overline{a, b}$ Diferença estatística $(p<0,05)$ entre os grupos, no mesmo momento. ${ }^{A, B}$ Diferença estatística $(\mathrm{p}<0,05)$ entre os momentos, no mesmo grupo. recebeu o acidificante em nenhum momento -, houve diminuição do $\mathrm{pH}$ em relação à normalidade para a espécie ovina $(6,0-8,5)$, conforme descrito por Garcia-Navarro (2005). Isso se explica pela dieta rica em grãos fornecida no experimento, que promove a acidificação da urina, comparada à alimentação composta somente por volumoso, o que a torna mais alcalina (Araújo et al., 2009). Notou-se decréscimo expressivo do $\mathrm{pH}$ urinário do grupo $\mathrm{CA}(5,79)$, que recebeu CA, em comparação ao grupo-controle $(6,52)$, evidenciado principalmente a partir do M3.

Em estudo recente, Ferreira et al. (2011) também observaram a acidificação do $\mathrm{pH}$ urinário, em ovinos tratados com $400 \mathrm{mg} / \mathrm{kg} / \mathrm{PV}$ de CA/dia. Houve diminuição do $\mathrm{pH}$, a partir do segundo dia da administração, e os valores se mantiveram menores do que 6,0 durante todo o experimento, o que difere de Mavangira et al. (2010), que não conseguiram acidificar a urina de caprinos com uso de $200 \mathrm{mg} / \mathrm{kg} / \mathrm{PV}$ de CA, porém, o conseguiram com $500 \mathrm{mg} /$ $\mathrm{kg} / \mathrm{PV}$. No presente trabalho, a acidificação urinária foi verificada logo na primeira aferição, sete dias após o início do tratamento; e, no grupo $\mathrm{CA}$, que recebeu o produto durante todo o período experimental, o $\mathrm{pH}$ se manteve menor do que 6,1 , com a dose de $400 \mathrm{mg} / \mathrm{kg} / \mathrm{PV} /$ dia.

Não foi possível relacionar o aparecimento de proteína na urina com o tratamento realizado. Isto porque, no M0, considerado basal, foi quando se observou maior número de animais com proteína nas amostras de urina, que foi de 25/40 no grupo CA e 7/20 no grupo-controle. A proteinúria geralmente é encontrada especialmente nos animais alimentados com altos teores de proteína (Botelho et al. 2012), o que aconteceu no presente trabalho, visto que a dieta era composta por $20 \%$ PB. A proteinúria também se justifica nos casos de glomerulonefrite, nefrite intersticial, pielonefrite ou nefrose, em que as proteínas atravessam a membrana glomerular, as de baixo peso molecular são reabsorvidas e as restantes são excretadas na urina (Garcia-Navarro 2005). Porém, os animais não apresentaram sinais clínicos destas enfermidades do trato urinário, embora 7/40 animais do grupo CA e 4/20 do grupo-controle apresentassem sinéquias glomerulares de grau leve. Além disso, 15/40 cordeiros do grupo CA e 5/20 do grupo-controle mostraram proteína na luz tubular em grau leve, portanto, pode-se inferir que a proteinúria é pré-renal e está relacionada à alta ingestão proteica da dieta.

Os outros fatores a serem considerados no resultado positivo quanto à proteína são inflamações no trato urogenital, hemoglobinúria e hematúria que influenciam o teste, devido à existência de exsudatos proteicos (Garcia-Navarro 2005, Guimarães et al. 2012). No M0, observaram-se animais com sangue oculto positivo na urina, em quantidade semelhante aos que apresentaram proteinúria que, por sua vez, também foi coincidente com o número de animais que tiveram maior quantidade de hemácias na urina. A partir do M1, não se observou sangue oculto na maioria das amostras, e não houve diferença entre os grupos e momentos de colheita. Na maioria das amostras, havia presença de hemácias, porém, em pouca quantidade visualizada por campo e, portanto, sem significado clínico. Nenhum animal apresentou hematúria, caracterizada por observação de 
coloração avermelhada na urina, durante o experimento.

0 transporte foi considerado como grande fator estressante aos animais (Paes et al. 2012), tanto por problemas traumáticos quanto pelo esforço muscular para manter o equilíbrio, e poderia explicar esses achados, embora os animais estivessem já com 14 dias de período adaptativo. Além disso, o que se observou é que os animais, no início do período experimental, mostravam comportamento de dominância e sodomia. Talvez esta seja a causa mais provável do aumento da proteína, sangue oculto e do número de hemácias no M0, já que nos momentos posteriores tendeu à normalidade (Gonsalves Neto et al. 2009).

Com relação à análise dos sedimentos da urina, as células de descamação que foram encontradas com maior frequência foram as uretrais e renais, seguidas das vesicais, enquanto as células da pelve apareceram raramente, em poucos animais. As células prostáticas estavam ausentes de todas as amostras colhidas (420/420), provavelmente em consequência da idade dos animais (Garcia-Navarro 2005). As células uretrais estiveram presentes em todas as amostras de urina colhidas neste experimento, principalmente em razão do método de colheita por micção natural, realizado conforme descrito por Garcia-Navarro(2005). Os resultados da contagem das células de descamação não possibilitaram estabelecer relação com os grupos estudados, nem ao longo dos momentos, pois não houve diferença exacerbada no comportamento das variáveis entre as análises. Os espermatozoides foram encontrados em pouca quantidade, porém, não têm relevância para o presente estudo. Normalmente as células estão presentes em pouca quantidade na urina (Garcia-Navarro 2005), portanto, pode-se dizer que as urinálises apresentaram valores normais para a espécie.

Todas as amostras (420/420) de urina apresentaram bactérias, e a maioria delas foi classificada como rara ou com uma cruz, em ambos os grupos estudados e, em menor número, duas cruzes. Bactérias classificadas como raras na lâmina do sedimento urinário foram consideradas como achado normal, o que indica contaminação superficial em amostras colhidas por micção natural, assim como se procedeu neste estudo. Se houvesse infecção urinária nos animais, a quantidade de bactérias seria maior do que a encontrada (Garcia-Navarro 2005, Araújo et al. 2009).

Houve presença de leucócitos também em todas as urinálises. Isto foi comprovado pelos achados de aglomerados leucocitários, porém não houve predominância celular em nenhum grupo. Os achados de hemácias e leucócitos nas amostras de urina dos animais não ressaltaram nenhum padrão característico relacionado aos grupos experimentais. A maior quantidade de células (mais de 350 células/ campo e incontáveis) foi encontrada, inclusive, no M0, quando o tratamento não havia sido iniciado no grupo CA. Nesse momento, 13/40 ovinos do grupo CA e 5/20 do grupo-controle mostraram leucócitos incontáveis. A partir do M1, a maioria das amostras apresentou 10 a 50 células/ campo e 50 a 100 células/campo em ambos os grupos estudados. Antes da colheita de urina, procedia-se à lavagem do prepúcio com água, por isso, grande parte da contaminação bacteriana foi amenizada com esse procedimento, no entanto, prováveis inflamações locais do prepúcio, glande e até uretra não eram removidas. Se houvesse caso de uretrite, haveria células de descamação uretral, o que não ocorreu. Assim, pode-se justificar, no início do experimento, a presença significativa de leucocitúria e, menos relevante, de bacteriúria. A inflamação urogenital evidenciada pela leucocitúria no M0, porém sem sinais clínicos, pode ser atribuída a traumatismos durante o transporte (Paes et al. 2012) ou ao comportamento de dominância e sodomia (Gonsalves Neto et al. 2009), ou até pelo contato do prepúcio com a cama de maravalha durante o tempo em que os animais permaneciam em decúbito esternal. Talvez isso possa ser a justificativa para a leucocitúria, já que nos momentos posteriores o número de células/campo foi menor e se relaciona à normalidade, pois, a colheita foi por micção natural (Garcia-Navarro 2005).

Os cordeiros do grupo-controle não apresentaram muco nas amostras de urina (140/140). Entretanto, nas urinálises dos ovinos do grupo $\mathrm{CA}$, havia muco classificado como raro e uma cruz, a partir de M3. A presença de muco na urina é normal apenas nos equinos, principalmente nas éguas. Nas demais espécies, o muco pode surgir na primeira micção da manhã (Garcia-Navarro 2005). Durante o experimento, a urina era colhida pela manhã, quando a maioria dos animais estava em decúbito esternal, o que talvez possa justificar o aparecimento de muco em 35/280 amostras do grupo CA.

Encontraram-se cilindros (dos tipos granuloso, leucocitário, misto e hialino) no grupo CA partir de M2. Os cilindros são acúmulos de proteína e material celular formados nos túbulos renais, e denotam lesão tubular. Geralmente, são raros nos ruminantes, em razão da alcalinidade da urina (Araújo et al. 2009). No entanto, sua presença foi observada nas amostras de urina dos animais do presente trabalho, que apresentaram urina mais ácida, mesmo sem o uso do cloreto de amônio, pela ingestão de ração rica em concentrado. A maior quantidade de amostras com cilindros foi detectada no M6 do grupo CA (11/40). Houve predominância do tipo de cilindro granuloso, evidenciado por $22 / 280$ amostras do grupo CA. Apenas um animal do grupo CA apresentou cilindro hialino. Apenas 4/280 das urinálises do grupo CA mostraram duas cruzes de cilindros, e as demais foram classificadas como raras e uma cruz quanto à presença de cilindros. Nenhuma amostra de urina do grupo-controle apresentou cilindros em nenhum momento.

Tanto a presença de cilindros, como a de muco nos animais do grupo CA mostrou que pode existir agressão tubular pelo CA, embora apenas um animal de ambos os grupos apresentasse degeneração tubular leve na histopatologia. Se houvesse lesão tubular renal pelo consumo deste acidificante urinário, provavelmente, haveria maior quantidade de animais com degeneração e necrose tubular nos animais do grupo CA. Detectou-se necrose tubular leve e moderada em 20/40 ovinos do grupo CA e em 16/20 cordeiros do grupo-controle. A deposição de restos celulares é um fator extremamente importante para a formação do núcleo orgânico de urólito (Freeman et al. 2010).

Os cristais estavam presentes no grupo-controle, em maior quantidade no M6. A presença e o tipo de cristais es- 
tão diretamente relacionados ao desenvolvimento da urolitíase e à composição do cálculo (Garcia-Navarro 2005). 0 pH da urina também interfere no tipo de cristal, pois é influenciado pela dieta. Os mais comumente encontrados em ruminantes são os de estruvita, carbonatos e silicatos, em consequência da alcalinidade da urina (Araújo et al. 2009). Porém, no presente estudo a predominância nos dois grupos foi do tipo fosfato triplo, que pode se formar em $\mathrm{pH}$ alcalino, neutro ou levemente ácido, assim como o encontrado por Antonelli et al. (2012). Este tipo de cristal foi visualizado em 7,5\% (21/280) das amostras de urina dos animais do grupo CA e em 25,7\% (36/140) do grupo-controle. 0 cristal de carbonato de cálcio é formado em urina alcalina e foi detectado apenas na urinálise de um cordeiro do grupo-controle, que não recebeu acidificante urinário.

Mavangira et al. (2010) não encontraram associação entre a suplementação de CA e a presença de cristais na urina. Porém, observaram maior quantidade de cristais (fosfato triplo e oxalato de cálcio) em animais que não receberam o produto, fato corroborado pelo presente estudo. 0 grupocontrole $(27 \%-37 / 140)$ apresentou maior quantidade de animais com cristalúria ao longo dos momentos, em relação ao grupo CA (8\% - 21/280). Apenas os animais do grupo-controle mostraram quatro cruzes de cristais nas suas amostras de urina. No entanto, Mavangira et al. (2010) não realizaram urinálise antes do início do tratamento e, como no presente trabalho procederam ao M0. Assim esses autores não conseguiram determinar o que havia na urina antes do estudo.

\section{Ureia e creatinina séricas}

Os valores de creatinina (Quadro 2), durante todo o experimento, permaneceram abaixo da faixa de normalidade - de 1,2 a 1,9mg/dL - descrita para a espécie por Kaneko et al. (2008), enquanto os resultados da mensuração de ureia (Quadro 3) se mostraram acima dos valores de normalidade - de 17,12 a 42,8mg/dL -, em todos os grupos e momentos.

Os resultados de creatinina do grupo CA foram menores após maior tempo de uso do CA, o que pode ser explicado pelo efeito diurético promovido por este sal (Stratton-Phelps \& House 2004). Porém, o grupo-controle, que não recebeu o tratamento, também mostrou valores mais baixos. Isto pode estar relacionado à maior ingestão de

\begin{tabular}{|c|c|c|c|c|}
\hline \multirow[t]{2}{*}{ M } & \multicolumn{2}{|c|}{ Grupo CA $(n=40)$} & \multicolumn{2}{|c|}{ Grupo controle $(n=20)$} \\
\hline & $\bar{x} \pm s$ & $M d$ & $\bar{x} \pm s$ & $M d$ \\
\hline M0 & $1,10 \pm 0,39$ & $0,99^{\mathrm{Aa}}$ & $0,98 \pm 0,54$ & $0,86^{\mathrm{Aa}}$ \\
\hline M1 & $1,11 \pm 0,37$ & $1,13^{\mathrm{Aa}}$ & $0,87 \pm 0,24$ & $0,85^{\mathrm{Ab}}$ \\
\hline M2 & $0,85 \pm 0,28$ & $0,83^{\mathrm{ABa}}$ & $0,73 \pm 0,10$ & $0,71^{\mathrm{Bb}}$ \\
\hline M3 & $0,96 \pm 0,91$ & $0,82^{\mathrm{ABa}}$ & $0,73 \pm 0,09$ & $0,72^{\mathrm{Bb}}$ \\
\hline M4 & $0,75 \pm 0,19$ & $0,73^{\mathrm{Ba}}$ & $0,69 \pm 0,11$ & $0,71^{\mathrm{Ba}}$ \\
\hline M5 & $0,76 \pm 0,17$ & $0,77^{\mathrm{Ba}}$ & $0,75 \pm 0,19$ & $0,81^{\mathrm{Aa}}$ \\
\hline M6 & $0,80 \pm 0,36$ & $0,73^{\mathrm{Ba}}$ & $0,73 \pm 0,23$ & $0,70^{\mathrm{Ba}}$ \\
\hline
\end{tabular}

$\overline{a, b}$ Diferença estatística $(p<0,05)$ entre os grupos, no mesmo momento. ${ }^{A, B}$ Diferença estatística $(\mathrm{p}<0,05)$ entre os momentos, no mesmo grupo.
Quadro 3. Médias ( $\bar{x}$ ), desvios-padrão (s) e medianas (Md)

de ureia $(\mathrm{mg} / \mathrm{dL})$ sérica, nos diferentes momentos de colheita, de ovinos confinados com e sem suplementação de cloreto de amônio (Grupo CA e Grupo controle)

\begin{tabular}{cccccc}
\hline M & \multicolumn{2}{c}{ Grupo CA $(\mathrm{n}=40)$} & & \multicolumn{2}{c}{ Grupo controle $(\mathrm{n}=20)$} \\
\cline { 2 - 3 } \cline { 6 - 7 } & $\bar{x} \pm s$ & $M d$ & & $\bar{x} \pm s$ & $M d$ \\
\hline M0 & $49,96 \pm 23,53$ & $44,18^{\mathrm{ABa}}$ & & $50,46 \pm 37,26$ & $43,20^{\mathrm{ABa}}$ \\
M1 & $45,71 \pm 19,32$ & $39,50^{\mathrm{Aa}}$ & & $45,57 \pm 12,46$ & $44,95^{\mathrm{ABa}}$ \\
M2 & $59,59 \pm 16,77$ & $56,10^{\mathrm{Ba}}$ & & $44,61 \pm 12,98$ & $45,70^{\mathrm{ABb}}$ \\
M3 & $45,66 \pm 15,84$ & $44,90^{\mathrm{Aa}}$ & & $61,75 \pm 26,93$ & $62,70^{\mathrm{Ab}}$ \\
M4 & $55,48 \pm 16,73$ & $53,75^{\mathrm{ABa}}$ & & $66,95 \pm 18,16$ & $68,80^{\mathrm{Bb}}$ \\
M5 & $46,21 \pm 17,12$ & $42,35^{\mathrm{Aa}}$ & & $51,50 \pm 21,47$ & $46,55^{\mathrm{ABa}}$ \\
M6 & $51,35 \pm 23,31$ & $47,55^{\mathrm{ABa}}$ & & $54,87 \pm 25,38$ & $48,10^{\mathrm{ABa}}$
\end{tabular}

$\overline{a, b}$ Diferença estatística $(p<0,05)$ entre os grupos, no mesmo momento. ${ }^{A, B}$ Diferença estatística $(\mathrm{p}<0,05)$ entre os momentos, no mesmo grupo.

água, observada durante o experimento, em consequência da apresentação farelada da ração total. Embora não se tenha mensurado a quantidade exata de água ingerida pelos ovinos durante o experimento, notou-se a necessidade de reposição de água nos cochos com maior frequência. Segundo Araújo et al. (2009), quanto maior a ingestão de proteína ou nitrogênio não proteico, maior será a ingestão de água, com aumento da produção urinária. Assim, os animais, provavelmente, urinaram um volume maior, excretaram mais creatinina e, consequentemente os níveis séricos diminuíram (Ferreira et al. 2014b). A avaliação do volume do débito urinário diário, para comprovar o efeito diurético do CA, no presente estudo, deveria ser realizada pelo uso de gaiola metabólica (Louvandini \& Vitti 1994, Stratton-Phelps \& House 2004), para mensurar o volume de água ingerido e de urina excretada.

As médias e medianas das concentrações da ureia sérica se mostraram maiores do que o padrão de referência para a espécie, porém, os animais não apresentaram sintomatologia clínica de alteração da função renal. Os níveis aumentados de ureia neste caso podem ser relacionados à alta ingestão proteica da dieta, que provoca proteinúria pré-renal. Os animais foram alimentados durante o experimento com ração total com $20 \% \mathrm{~PB}$, correspondente ao nível indicado (12 a 24\% PB) para crescimento e terminação de cordeiros de (Zundt et al., 2002; Prado et al., 2013).

A creatinina é um marcador de lesão renal mais eficaz que a ureia, pois em animais sadios ela não é reabsorvida pela parede das células dos túbulos renais, além de não ser influenciada pela dieta (Kirsztajn et al. 2007, Braun et al. 2010). Embora a creatinina se mostre elevada apenas quando há comprometimento de mais de $70 \%$ dos néfrons (Kozloski et al. 2005), a análise conjunta da ureia e ausência do quadro clínico compatível com nefropatia dos animais permitiu excluir disfunções renais durante o experimento. Isso era esperado, uma vez que não houve obstrução do fluxo urinário por cálculos. No entanto, foram encontradas alterações significativas na urinálise, como a presença de cilindros granulosos que indicam lesão tubular renal, e cristais.

Sacco \& Lopes (2011) não observaram aumento das concentrações séricas de creatinina $(1,54 \mathrm{mg} / \mathrm{dL})$, em grupo de bovinos Guzerá com urolitíase em consequência da dureza da água, assim como Dória et al. (2007), que rela- 
taram um caso em carneiro. Porém, este animal foi desobstruído apenas com tratamento com antiespasmódico. Já em outros dois casos de caprinos da raça Boer, relatados por Dória et al. (2007), houve aumento expressivo de ureia $(442,95 \mathrm{mg} / \mathrm{dL})$ e creatinina $(5,65 \mathrm{mg} / \mathrm{dL})$. Guimarães et al. (2012) detectaram azotemia em 66 animais estudados, com média de 4,71mg/dL de creatinina e 185,61mg/dL de ureia. Apesar das dosagens de ureia e creatinina atingirem valores elevados, estes foram relacionados à estase urinária e consequente reabsorção destes compostos, o que caracteriza azotemia pós-renal e não propriamente insuficiência renal (Guimarães et al., 2012).

George et al. (2007) notaram aumento de ureia e creatinina em 107 caprinos com urolitíase, com média de $73,2 \mathrm{mg} / \mathrm{dL}$ e $6,3 \mathrm{mg} / \mathrm{dL}$, respectivamente. Observou-se azotemia $(184,84 \mathrm{mg} / \mathrm{dL}$ de ureia e $3,64 \mathrm{mg} / \mathrm{dL}$ de creatinina) no perfil renal sérico em um ovino macho, com obstrução uretral, descrito por Sousa et al. (2011). Streeter et al. (2002) também constataram aumento de creatinina $(3,9 \mathrm{mg} / \mathrm{dL})$ em caprino de três meses de idade com urolitíase obstrutiva.

\section{Exame macroscópico do sistema urinário}

O exame macroscópico do sistema urinário dos ovinos dos dois grupos experimentais (Quadro 4) revelou cálculos de aspecto arenoso nos rins (Fig.1 e 2). Outras alterações patológicas macroscópicas foram encontradas, como congestão de medular renal, alteração da definição córtico-medular renal e dilatação da pelve, em ambos os grupos; no

Quadro 4. Alterações macroscópicas do sistema urinário no post-mortem de ovinos confinados com e sem suplementação de cloreto de amônio (Grupo CA e Grupo controle)

\begin{tabular}{lcc}
\hline \multicolumn{1}{c}{ Alterações } & $\begin{array}{c}\text { Grupo CA } \\
(\mathrm{n}=40)\end{array}$ & $\begin{array}{c}\text { Grupo controle } \\
(\mathrm{n}=20)\end{array}$ \\
\hline Cálculos renais (pelve) & $12,5 \%(5 / 40)^{\mathrm{a}}$ & $25 \%(5 / 20)^{\mathrm{b}}$ \\
Dilatação da pelve renal & $7,5 \%(3 / 40)^{\mathrm{a}}$ & $5 \%(1 / 20)^{\mathrm{a}}$ \\
Perda da definição córtico-medular & $15 \%(6 / 40)^{\mathrm{a}}$ & $20 \%(4 / 20)^{\mathrm{a}}$ \\
Hidroureter e hidronefrose & $0 \%(0 / 40)^{\mathrm{a}}$ & $5 \%(1 / 20)^{\mathrm{a}}$ \\
Congestão da medular renal & $30 \%(12 / 40)^{\mathrm{a}}$ & $30 \%(6 / 20)^{\mathrm{a}}$
\end{tabular}

$\overline{\mathrm{a}, \mathrm{b}}$ Diferença estatística entre as porcentagens das colunas, pelo teste $\mathrm{Z}$ com correção de Bonferroni $(\mathrm{p}<0,05)$.

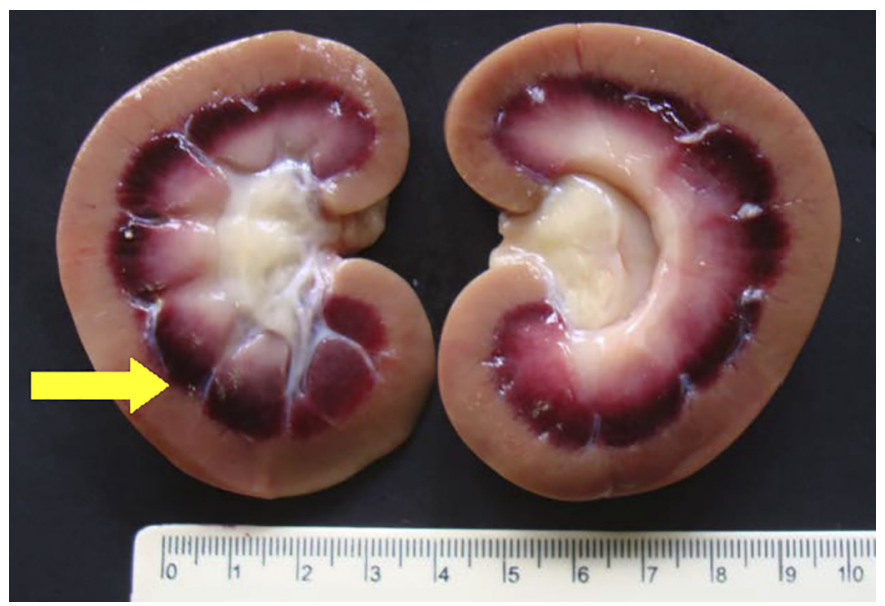

Fig.1. Rim de um ovino do grupo CA, que apresenta congestão da medular e pequenos cálculos (seta).

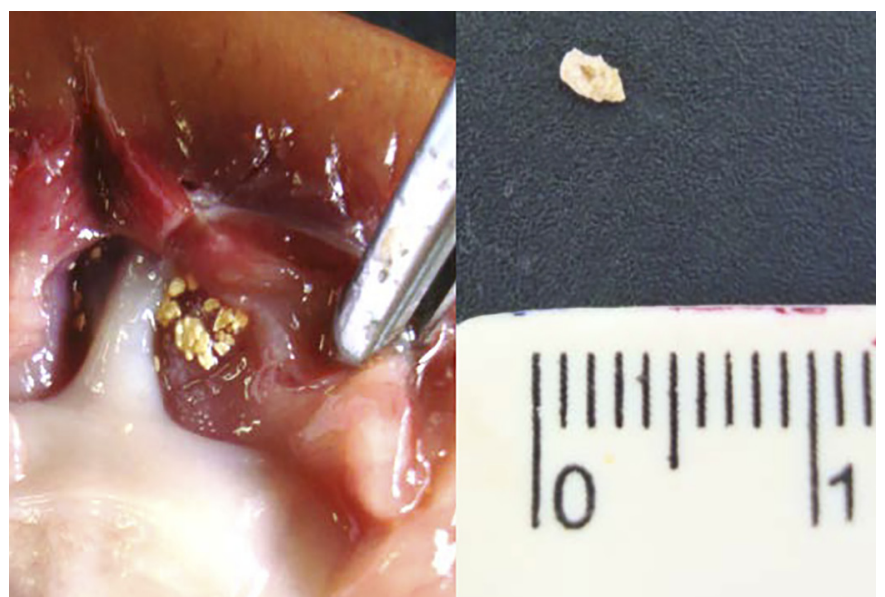

Fig.2. Presença de cálculos na pelve e medular do rim de um ovino do grupo CA, e amostra de cálculo.

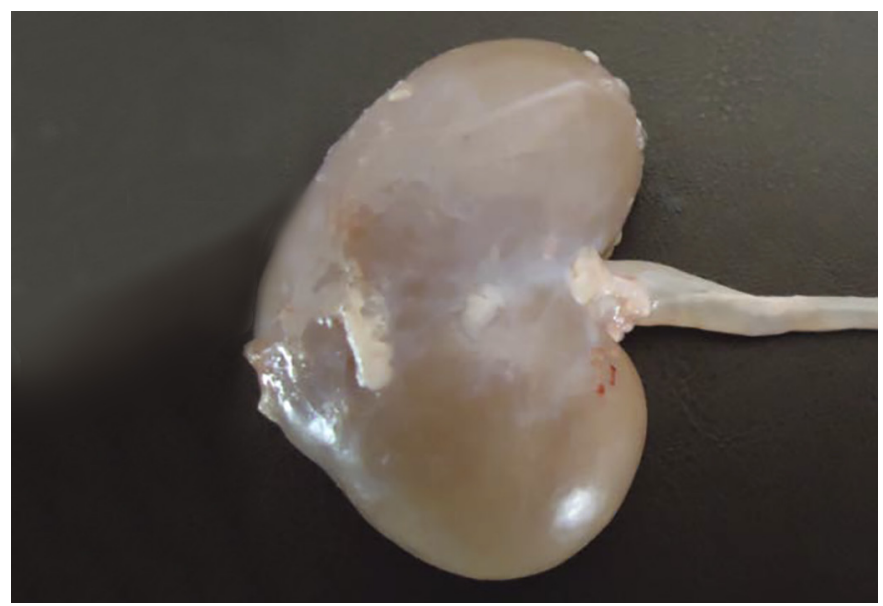

Fig.3. Rim direito de um ovino do grupo-controle, com dilatação do ureter, devido à presença de cálculos. Nota-se o aumento de volume renal.

grupo-controle, um animal apresentou hidronefrose com dilatação unilateral de ureter (Fig.3).

Obstrução parcial ou total de ureter provoca dor intensa pela migração dos cálculos dos rins até a bexiga, em qualquer espécie animal (Ewoldt et al. 2008). Apesar disso, um cordeiro do grupo-controle apresentou hidroureter e discreta hidronefrose no post-mortem (Fig.3), e não se detectou manifestação dolorosa ou diminuição de apetite nesse animal, até o final do período de confinamento. Isso corrobora com a descrição da manifestação clínica de caprinos após obstrução ureteral unilateral total e bilateral parcial experimental, relatada por El-Kammar et al. (2012). Nesse estudo, os autores referiram que os animais ficaram deprimidos, apresentaram tremores e arqueamento do dorso, no primeiro dia após a obstrução experimental por ligadura cirúrgica do ureter, porém, a partir do quarto dia, todos os caprinos passaram a se alimentar, tomar água, defecar e urinar normalmente. Assim, pode-se dizer que o cordeiro do presente trabalho pode ter apresentado dor entre os períodos de observação clínica diária, nos últimos momentos de colheita do experimento, enquanto ocorria o processo de obstrução parcial unilateral do ureter, entretanto, seu 
comportamento estava normalizado nos dias anteriores à necropsia.

As alterações macroscópicas dos rins corroboraram os dados presentes na literatura (Loretti el al. 2003, Riet-Correa et al. 2008, Assis et al. 2009, Guimarães et al. 2012), com exceção dos achados de necropsia relacionados à obstrução ou ruptura uretral e ruptura vesical, pois, no presente estudo, não houve detecção clínica da obstrução do fluxo urinário, embora tenham sido encontrados cálculos, principalmente na pelve renal dos animais.

Os achados patológicos dos rins deste estudo, como congestão da medular renal e hemorragia, corroboram as alterações descritas por Sahinduran et al. (2007) em bovinos com urolitíase. No presente trabalho, observaram-se urólitos apenas no post-mortem, localizados na pelve e nos cálices renais, assim como foi relatado por esses autores.

Os achados necroscópicos deste trabalho foram semelhantes aos achados descritos nos estudos de Dória et al. (2007), Riet-Correa et al. (2008) e Guimarães et al. (2012), sobre ovinos acometidos por urolitíase em Jaboticabal, SP, Paraíba e Pernambuco. Estes autores, no entanto, citaram ocorrência de pielonefrite, cistite hemorrágica difusa, presença de urólitos na bexiga e uretra, o que não foi observado no presente estudo.

\section{Exame microscópico do sistema urinário}

No exame histopatológico do sistema urinário, observaram-se diversas alterações nos rins e bexiga que estão descritas nos Quadros 5 e 6, respectivamente, e ilustradas nas Figuras 4 a 9. Os fragmentos de ureter e uretra peniana não mostraram alterações microscópicas. Isso se deve à au-

Quadro 5. Alterações microscópicas dos rins de ovinos confinados com e sem suplementação de cloreto de amônio (Grupo CA e Grupo controle)

\begin{tabular}{|c|c|c|c|}
\hline \multirow[t]{2}{*}{ Alterações } & \multirow[t]{2}{*}{ Grau } & \multicolumn{2}{|c|}{ Grupos } \\
\hline & & $\begin{array}{l}\text { Grupo CA } \\
(n=40)\end{array}$ & $\begin{array}{l}\text { Grupo controle } \\
\qquad(\mathrm{n}=20)\end{array}$ \\
\hline \multirow[t]{3}{*}{ Congestão vascular } & Ausente & $90 \%(36 / 40)^{a}$ & $55 \%(11 / 20)^{\mathrm{b}}$ \\
\hline & Leve & $7,5 \%(3 / 40)^{a}$ & $30 \%(6 / 20)^{\mathrm{b}}$ \\
\hline & Moderado & $2,5 \%(1 / 40)^{\mathrm{a}}$ & $15 \%(3 / 20)^{a}$ \\
\hline \multirow[t]{4}{*}{ Dilatação tubular } & Ausente & $95 \%(38 / 40)^{a}$ & $90 \%(18 / 20)^{\mathrm{a}}$ \\
\hline & Leve & $0 \%(0 / 40)^{a}$ & $5 \%(1 / 20)^{a}$ \\
\hline & Moderado & $2,5 \%(1 / 40)^{\mathrm{a}}$ & $5 \%(1 / 20)^{a}$ \\
\hline & Acentuado & $2,5 \%(1 / 40)^{\mathrm{a}}$ & $0 \%(0 / 20)^{a}$ \\
\hline \multirow[t]{2}{*}{ Degeneração tubular } & Ausente & $97,5 \%(39 / 40)^{a}$ & $90 \%(19 / 20)^{a}$ \\
\hline & Leve & $2,5 \%(1 / 40)^{\mathrm{a}}$ & $10 \%(1 / 20)^{\mathrm{a}}$ \\
\hline \multirow[t]{3}{*}{ Necrose tubular } & Ausente & $50 \%(20 / 40)^{a}$ & $20 \%(4 / 20)^{\mathrm{b}}$ \\
\hline & Leve & $40 \%(16 / 40)^{a}$ & $70 \%(14 / 20)^{\mathrm{b}}$ \\
\hline & Moderado & $10 \%(4 / 40)^{\mathrm{a}}$ & $10 \%(2 / 20)^{a}$ \\
\hline \multirow{3}{*}{$\begin{array}{l}\text { Infiltrado inflamatório } \\
\text { mononuclear }\end{array}$} & Ausente & $62,5 \%(25 / 40)^{\mathrm{a}}$ & $60 \%(12 / 20)^{\mathrm{a}}$ \\
\hline & Leve & $27,5 \%(11 / 40)^{\mathrm{a}}$ & $30 \%(6 / 20)^{a}$ \\
\hline & Moderado & $10 \%(4 / 40)^{\mathrm{a}}$ & $10 \%(2 / 20)^{a}$ \\
\hline \multirow[t]{3}{*}{ Proteína na luz tubular } & Ausente & $62,5 \%(25 / 40)^{\mathrm{a}}$ & $70 \%(14 / 20)^{\mathrm{a}}$ \\
\hline & Leve & $37,5 \%(15 / 40)^{a}$ & $25 \%(5 / 20)^{\mathrm{a}}$ \\
\hline & Moderado & $0 \%(0 / 40)^{a}$ & $5 \%(1 / 20)^{a}$ \\
\hline \multirow[t]{2}{*}{ Sinéquias glomerulares } & Ausente & $82,5 \%(33 / 40)^{\mathrm{a}}$ & $80 \%(16 / 20)^{a}$ \\
\hline & Leve & $17,5 \%(7 / 40)^{\mathrm{a}}$ & $20 \%(4 / 20)^{\mathrm{a}}$ \\
\hline \multirow[t]{2}{*}{ Fibrose cortical } & Ausente & $87,5 \%(35 / 40)^{\mathrm{a}}$ & $100 \%(20 / 20)^{a}$ \\
\hline & Leve & $12,5 \%(5 / 40)^{\mathrm{a}}$ & $0 \%(0 / 40)^{a}$ \\
\hline
\end{tabular}

a,b Diferença estatística entre as porcentagens das colunas, pelo teste $\mathrm{Z}$ com correção de Bonferroni $(\mathrm{p}<0,05)$.
Quadro 6. Alterações microscópicas da bexiga de ovinos confinados com e sem suplementação de cloreto de amônio (Grupo CA e Grupo controle))

\begin{tabular}{llcc}
\hline \multirow{2}{*}{ Alterações } & Grau & \multicolumn{2}{c}{ Grupos } \\
\cline { 3 - 4 } & & $\begin{array}{c}\text { Grupo CA } \\
(\mathrm{n}=40)\end{array}$ & $\begin{array}{c}\text { Grupo controle } \\
(\mathrm{n}=20)\end{array}$ \\
\hline Congestão vascular & Ausente & $97,5 \%(39 / 40)^{\mathrm{a}}$ & $95 \%(19 / 20)^{\mathrm{a}}$ \\
& Leve & $2,5 \%(1 / 40)^{\mathrm{a}}$ & $5 \%(1 / 20)^{\mathrm{a}}$ \\
Infiltrado inflamatório & Ausente & $90 \%(36 / 40)^{\mathrm{a}}$ & $90 \%\left(18 / 20^{\mathrm{a}}\right.$ \\
mononuclear & Leve & $10 \%(4 / 40)^{\mathrm{a}}$ & $10 \%(2 / 20)^{\mathrm{a}}$
\end{tabular}

$\overline{\mathrm{a}, \mathrm{b}}$ Diferença estatística entre as porcentagens das colunas, pelo teste $\mathrm{Z}$ com correção de Bonferroni $(p<0,05)$

sência de lesões macroscópicas, como obstrução uretral e ureteral por cálculos, com exceção de um animal do grupo-controle, que apresentou obstrução parcial unilateral do ureter, conforme mostrado na Figura 3.

As alterações de maior relevância em ambos os grupos, em ordem crescente, foram: sinéquias glomerulares, congestão vascular, proteína na luz tubular, infiltrado inflamatório mononuclear e necrose tubular. As demais alterações microscópicas, como dilatação e degeneração tubular, e fibrose cortical mostraram pouca importância, em razão da baixa prevalência encontrada.

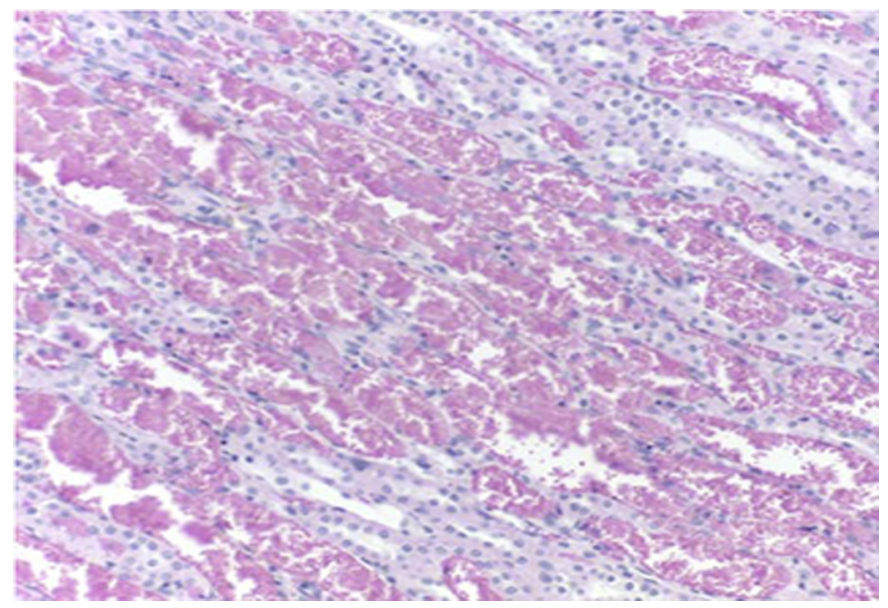

Fig.4. Congestão vascular renal em ovino. HE, obj.20x.

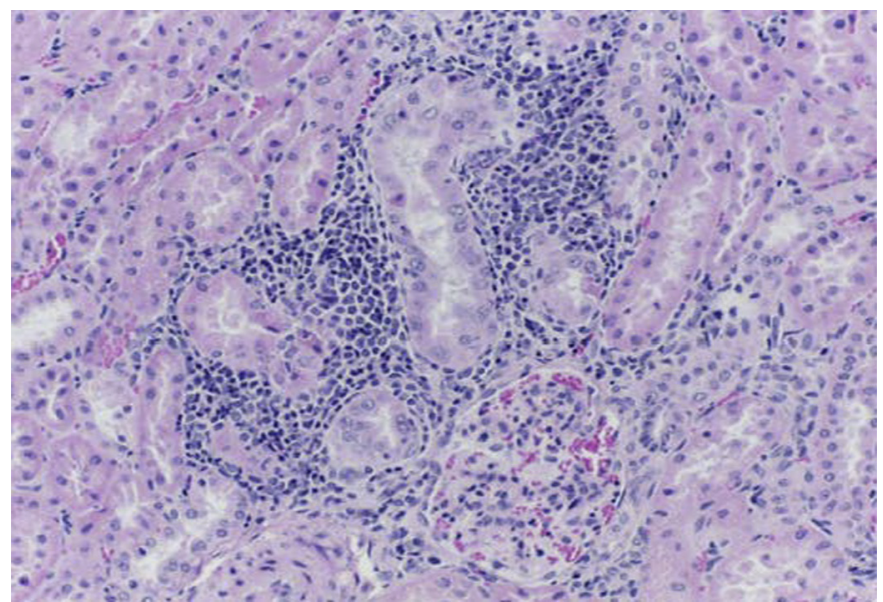

Fig.5. Infiltrado inflamatório mononuclear (linfocítico) renal em ovino. HE, obj.20x. 


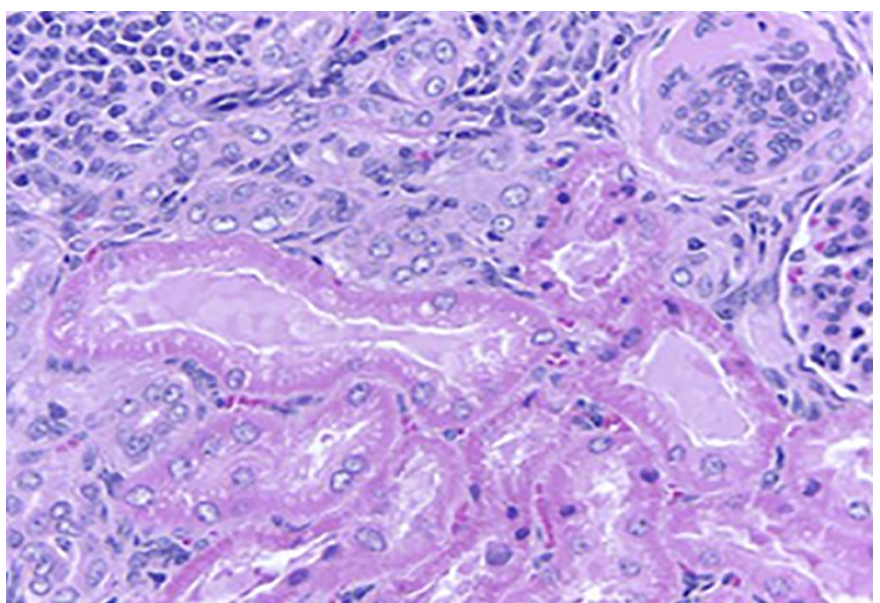

Fig.6. Necrose tubular rernal em ovino. HE, obj.40x.

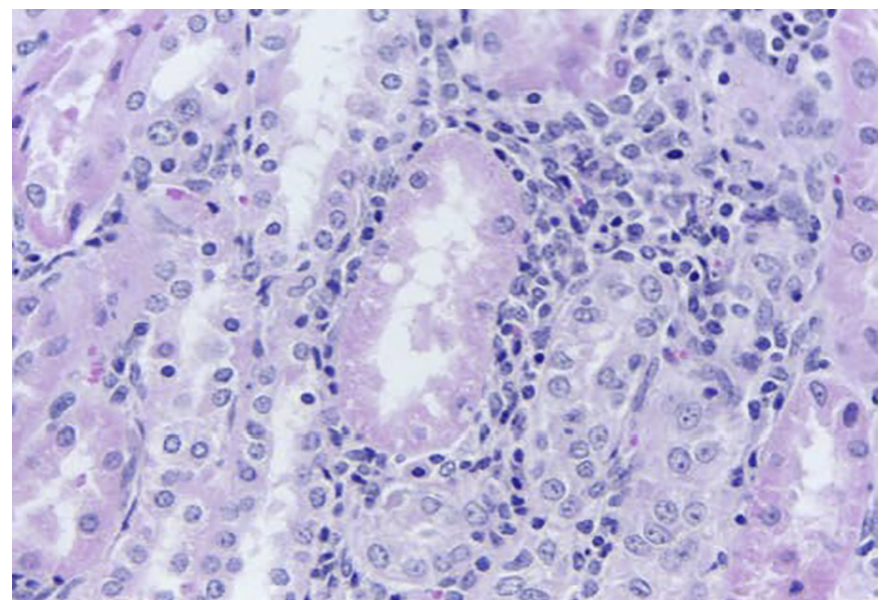

Fig.7. Proteína na luz tubular renal (material amorfo eosinofílico) em ovino. HE, obj.40x.

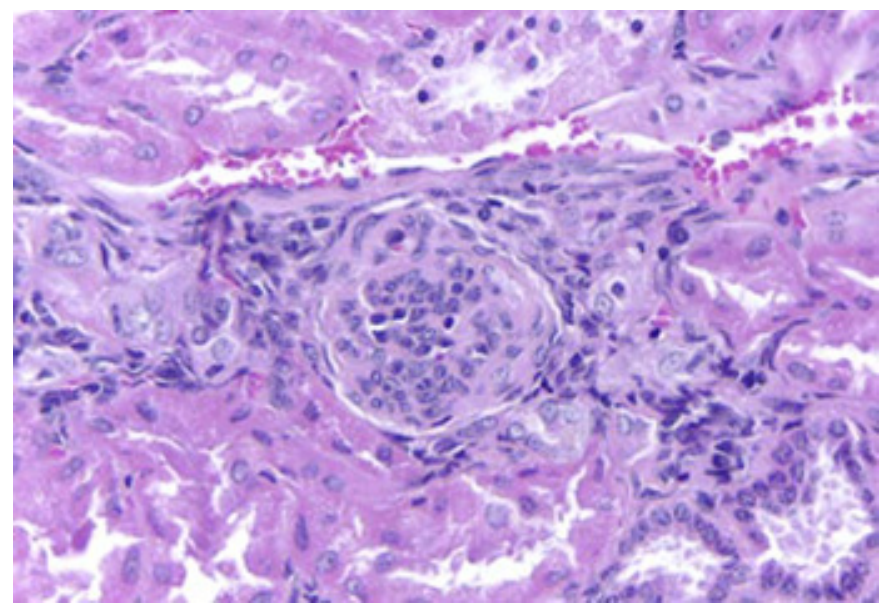

Fig.8. Sinéquia e esclerose glomerular renal em ovino. HE, obj.40x.

A congestão vascular (Fig.4) observada pode estar relacionada a processos inflamatórios (Maxie \& Newman 2007, Raekallio et al. 2010). Visualizou-se infiltrado inflamatório mononuclear (Fig.5), com predomínio de linfócitos e plasmócitos. Não se verificou presença de células polimorfonucleares, por se tratar possivelmente de lesões inflamatórias mais crônicas (Maxie \& Newman 2007). Observou-se fibro-

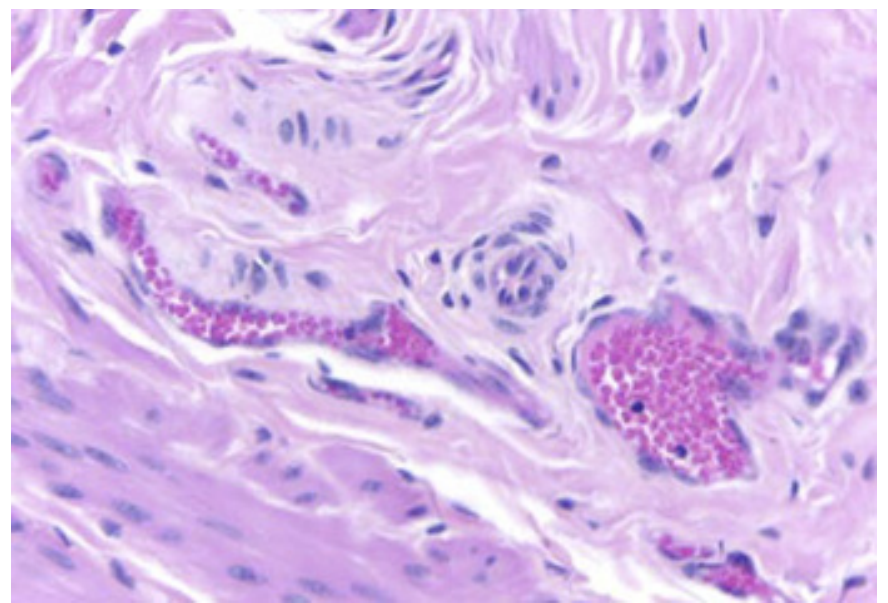

Fig.9. Congestão vascular na bexiga de ovino. HE, obj.40x.

se somente no grupo CA, porém, apenas em cinco animais. El-Kammar et al. (2012) também observaram infiltrado mononuclear e fibrose nos rins de caprinos com hidronefrose, causada por indução experimental de obstrução ureteral.

Observou-se necrose tubular (Fig.6) em 50\% dos ovinos do grupo CA e $80 \%$ do grupo-controle, que pode ser considerada a lesão renal mais relevante encontrada nos animais deste estudo, visto que foi encontrada em muitos animais e por se tratar de uma alteração irreversível.

A presença de proteína na luz tubular (Fig.7) apareceu de forma semelhante nos dois grupos, o que pode ser explicado pelo consumo da mesma dieta e pelo alto teor de PB (Braun et al. 2010, Botelho et al. 2012). A ocorrência de sinéquias glomerulares (Figura 8) é diretamente afetada pela alta ingestão proteica ( $20 \%$ PB), pois o animal acaba excretando o excesso de proteína ingerida pela urina, o que categoriza proteinúria pré-renal (Garcia-Navarro 2005), e danifica os glomérulos (Rabinowitz et al. 1973, Palviainen et al. 2012), contribuindo para a formação do núcleo proteico do urólito (Antonelli et al. 2012).

A hiperproteneimia também se manifestou com níveis elevados de ureia sérica, conforme mostra o Quadro 3. Esses achados sugeriram grau leve de glomerulonefrite, conforme Frelier et al. (1990) e Inkelmann et al. (2012), que encontraram hipoalbuminemia, hipocalcemia, hiperfosfatemia e uremia em quatro cordeiros com mesangiocapilar glomerulonefrite tipo I, corroborado pelo aumento de ureia observado no presente trabalho.

A presença de proteína na luz tubular também categoriza lesão tubular, pois, apenas proteínas de baixo peso molecular (albumina) ultrapassam o glomérulo, porém, elas são reabsorvidas pelas células epiteliais tubulares. A proteinúria pode resultar da diminuição da capacidade de reabsorção tubular ou de lesão tubular, mas a maioria das proteinúrias é uma consequência da alteração da filtração glomerular (Frelier et al. 1990). A proteinúria sem os achados de sedimento inflamatório urinário, que denotaria proteinúria pós-renal, é o marco principal da doença glomerular (Garcia-Navarro 2005).

Nas alterações vesicais (Quadro 6), notou-se congestão vascular leve (Fig.9) e infiltrado inflamatório mononuclear. 
A ausência de outras alterações pode ser justificada pela inexistência de lesões macroscópicas na bexiga, como cistite ou presença de cálculos (Maxie \& Newman 2007).

Embora não se tenham obtido casos de urolitíase obstrutiva durante o período experimental, o uso do CA não impediu a formação de cálculos renais, que foram visualizados no exame macroscópico. No entanto, detectou-se menor número de animais do grupo CA com necrose tubular renal do que o grupo-controle. Isso mostra que este acidificante urinário não predispõe ao desenvolvimento de lesões renais pelo seu uso contínuo na alimentação, mas que a dieta rica em grãos provoca alterações relevantes que foram detectadas no exame histopatológico.

Santarosa et al. (2008) e Barbosa et al. (2008) estudaram o perfil bioquímico renal e hepático, respectivamente, de ovinos confinados e suplementados com $\mathrm{CA}$, e não verificaram aumento de ureia, creatinina e das enzimas hepáticas. Afirmaram que este sal acidificante não provocou prejuízos aos rins e fígado de ovinos. No presente estudo, também não se observou aumento dos exames bioquímicos de função renal que justificassem as alterações encontradas no exame histopatológico, embora os níveis de ureia estivessem acima dos padrões de referência para a espécie ovina. Isso corrobora relatos da literatura, que afirmam existir aumento significativo das alterações nos exames de função renal, quando ocorre grande comprometimento dos néfrons, em cerca de 70\% (Kozloski et al. 2005, Braun et al. 2010) e, no presente estudo, as lesões microscópicas encontradas foram classificadas como leves na maioria dos animais.

Os achados histopatológicos dos rins, como congestão vascular, infiltrado inflamatório, degeneração e necrose tubular deste estudo, concordaram com os descritos por diversos autores que relataram casos de urolitíase em ruminantes (Dória et al. 2007, Silva et al. 2008, Assis et al. 2009 , Oliveira et al. 2013). Embora se tenha visualizado fibrose no rim em apenas um ovino do grupo CA, e dilatação tubular em dois animais, de ambos os grupos, Oliveira et al. (2013) também descreveram estas lesões em um bovino com urolitíase. Os mesmos autores referiram predominância de linfócitos, no infiltrado inflamatório, e presença de proteína na luz tubular, assim como ocorreu nos cordeiros do presente estudo. Apesar de se detectar alta porcentagem de animais com sinéquias glomerulares neste experimento, não se observou degeneração glomerular, como relataram Silva et al. (2008) sobre um bovino. As lesões histopatológicas da bexiga foram compatíveis com os descritos por Silva et al. (2008), que relataram infiltrado inflamatório e congestão da submucosa, porém, estes autores discutiram um caso de cistite secundária à obstrução total da uretra, o que não ocorreu no presente estudo.

\section{CONCLUSÕES}

Concluiu-se que a dieta rica em concentrado proporcionou a formação de cálculos, mas não de urolitíase obstrutiva.

Os exames de ureia e creatinina não mostraram alterações na função renal dos ovinos, durante o período de confinamento.
A urinálise mostrou alterações, como presença de cilindros granulosos, no grupo CA, e cristalúria (predominância de fosfato triplo) em ambos os grupos.

A dieta rica em grãos, com alto teor de proteína $(20 \%$ PB) provocou lesão renal, comprovada pela proteinúria na urinálise, e alta porcentagem de necrose tubular visualizada nos rins dos animais, além de outras alterações como sinéquias glomerulares e presença de proteína na luz tubular.

Os ovinos do grupo-controle, não suplementados com cloreto de amônio, tiveram maior comprometimento renal pelo consumo da dieta rica em grãos, conforme exame histopatológico renal e, por consequência, este grupo apresentou maior porcentagem de animais com cristalúria e cálculos no post-mortem.

Deve-se atentar para a alimentação rica em grãos por períodos prolongados, como ocorre com reprodutores e animais de elite, pois pode provocar lesões renais, além da predisposição ao desenvolvimento da urolitíase; comprovou-se que esta dieta, fornecida no confinamento por 56 dias, foi capaz de provocar lesão renal, visualizada nos exames macro e microscópico, além da urinálise que mostrou a presença de cilindros granulosos que não afetaram a funcionalidade renal e, consequentemente, não prejudicaram o crescimento nem a terminação dos cordeiros.

Agradecimentos.- À FMVZ/Unesp-Botucatu, pela cessão de estrutura física e equipamentos utilizados para a realização do experimento. À FAPESP (Fundação de Amparo à Pesquisa do Estado de São Paulo), pela bolsa de mestrado concedida (Processo 2012/24985-4).

\section{REFERÊNCIAS}

Antonelli A.C., Barrêto Júnior R.A., Mori C.S., Sucupira M.C.A., Marcello A.C.S. \& Ortolani E.L. 2012. Efeito de diferentes fontes energéticas na predisposição para urolitíase em cabritos. Ciênc. Anim. Bras. 13:487493.

Araújo P.B., Pereira D.S., Teixeira M.N., Coelho M.C.O.C. \& Alencar S.P. 2009. Urinálise como instrumento auxiliar no diagnóstico de enfermidades em pequenos ruminantes. Med. Vet., Recife. 3:30-38.

Assis A.C.O., Silva T.R., Aguiar G.M.N., Melo D.B., Almeida F.C., Medeiros J.M. \& Nóbrega Neto P.I. 2009. Urolitíase obstrutiva em bovinos no semi-árido paraibano. Anais do VIII Congresso Brasileiro de Buiatria, Ciênc. Anim. Bras. 34(Supl.1):99-106.

Barbosa C.C., Goncalves R.C., Ferreira D.O.L., Santarosa B.P. \& Dias A. 2008. Perfil bioquímico hepático em ovinos confinados tratados com cloreto de amônio e vitamina C. Anais XX Congresso de Iniciação Científica da Universidade Estadual Paulista, São José dos Campos/SP.

Belknap E.B. \& Pugh D.G. 2005. Enfermidades do sistema urinário, p.287-310. In: Pugh D.G. (Ed.), Clínica de Ovinos e Caprinos. Roca, São Paulo.

Botelho G.G., Botelho C.M., Botelho C.F.M. \& Paz J.G. 2012. Relação proteína/creatinina urinária ( $\mathrm{PU} / \mathrm{CrU}$ ) em bovinos leiteiros. Revta Bras. Med. Vet. 34(2):121-126.

Braun J.P., Trumela C. \& Bézille P. 2010. Clinical biochemistry in sheep: a selected review. Small Rumin. Res. 92:10-18.

Dória R.G.S., Canola P.A., Dias D.P.M., Pereira R.N. \& Valadão C.A.A. 2007. Técnicas cirúrgicas para urolitíase obstrutiva em pequenos ruminantes: relato de casos. Arq. Bras. Med. Vet. Zootec. 59:1425-1432.

El-Kammar M.H., Alsafy M.A.M., Mohammed M.I. \& El-Neweshy M.S. 2012. Ureteric obstruction and hydronephrosis in Baladi goats: topographical anatomy, ultrasonographical, hematological and pathological findings. Small Rumin. Res. 104:169-178. 
Ewoldt J.M., Jones M.L. \& Miesner M.D. 2008. Surgery of obstructive urolithiasis in ruminants. Vet. Clin. North Am., Food Anim. Pract. 24:455-465.

Feitosa F.L.F. 2014. Semiologia veterinária: a arte de diagnóstico. $3 \underline{\text { a }}$ ed. Roca, São Paulo. 627p.

Ferreira D.O.L. 2009. Avaliação da acidificação urinária em ovinos com a utilização de três tratamentos. Dissertação de Mestrado, Faculdade de Medicina Veterinária e Zootecnia, Unesp-Botucatu, SP. 106p.

Ferreira D.O.L., Santarosa B.P., Moraes L.F., Takahira R.K., Amorim R.M., Chiacchio S.B. \& Gonçalves R.C. 2011. Avaliação da acidificação urinária em ovinos com cloreto de amônio, vitamina C e associação destes. Anais 38o Congresso Brasileiro de Medicina Veterinária (Conbravet), Florianópolis, SC [s.p.). (Resumo expandido)

Ferreira D.O.L. 2013. Modelo experimental de urolitíase em ovinos - estudo clínico, laboratorial e hemogasométrico. Tese de Doutorado, Faculdade de Medicina Veterinária e Zootecnia, Unesp-Botucatu, SP. 199p.

Ferreira D.O.L., Santarosa B.P., Sacco S.R., Dias A., Amorim R.M., Chiacchio S.B., Lisbôa J.A.N. \& Gonçalves R.C. 2014a. Efeito da suplementação de cloreto de amônio sobre os equilíbrios eletrolítico e ácido-básico e o pH urinário de ovinos confinados. Pesq. Vet. Bras. 34(8):797-804.

Ferreira D.O.L., Santarosa B.P., Belotta A.F., Mamprim M.J., Silva A.A., Dias A., Chiacchio S.B. \& Gonçalves R.C. 2014b. Alterações ultrassonográficas renais e vesicais de ovinos confinados e suplementados com cloreto de amônio. Pesq. Vet. Bras. 34(Supl.1):99-106.

Freeman S.R., Poorea M.H., Young G.A. \& Anderson K.L. 2010. Influence of calcium $(0.6$ or $1.2 \%)$ and phosphorus $(0.3$ or $0.6 \%)$ content and ratio on the formation of urolithogenic compounds in the urine of Boer-cross goats fed high-concentrate diets. Small Rumin. Res. 93:94-102.

Frelier P.F., Armstrong D.L. \& Pritchard J. 1990. Ovine mesangiocapillary glomerulonephritis type I and crescent formation. Vet. Pathol. 27:26-34.

Garcia-Navarro C.E.K. 2005. Manual de Urinálise Veterinária. Varela, São Paulo. 95p.

George J.W., Hird D.W. \& George L.W. 2007. Serum biochemical abnormalities in goats with uroliths: 107 cases (1992-2003). J. Am. Vet. Med. Assoc. 230(1):101-106.

Gonsalves Neto J., Teixeira F.A., Nascimento P.V.N. \& Marques J.A. 2009. Comportamento social dos ruminantes (Artigo no. 096). Revta Eletrôn. Nutritime 4(6):1039-1055.

Guedes Jr F.S., Cruz D.S., Rodrigues M.M.P., Silva L.M., Amorim R.L., Vianna P.T.G. \& Castiglia Y.M.M. 2012. Renal histology and immunohistochemistry after acute hemorrhage in rats under sevoflurane and ketoprofen effect. Acta Cirurgica Brasileira 27(1):37-42.

Guimarães J.A., Mendonça C.L., Guaraná E.L.S., Dantas A.C., Costa N.A., Câmara A.C.L., Farias C.C. \& Afonso J.A.B. 2012. Estudo retrospectivo de 66 casos de urolitíase obstrutiva em ovinos. Pesq. Vet. Bras. 32:824830.

Inkelmann M.A., Kommers G.D., Trost M.E., Barros C.S.L., Fighera R.A., Irigoyen L.F. \& Silveira I.P. 2012. Lesões do sistema urinário em 1.063 cães. Pesq. Vet. Bras. 32(8):761-771.

Kaneko J.J., Harvey J.W. \& Bruss M.L. 2008. Clinical Biochemistry of Domestic Animals. 6th ed. Academic, San Diego. 916p.

Kannan K.V.A. \& Lawrence K.E. 2010. Obstructive urolithiasis in a Saanen goat in New Zealand, resulting in a ruptured bladder. N. Z. Vet. J. 58:269271.

Kinsley M.A., Semevolos S., Parker J.E., Duesterdieck-Zellmer K. \& Huber M. 2013. Use of plain radiography in the diagnosis, surgical management, and postoperative treatment of obstructive urolithiasis in 25 goats and 2 sheep. Vet. Surgery 42:663-668.

Kirsztajn G.M. 2007. Avaliação do ritmo de filtração glomerular. J. Bras. Patol. Med. Lab. 43(4):257-264.

Kozloski G.V., Fiorentini G., Härter C.J. \& Sanchez L.M.B. 2005. Uso da creatinina como indicador da excreção urinária em ovinos. Ciência Rural 35(1):98-102.

Loretti A.P., Oliveira L.O., Cruz C.E.F. \& Driemeier D. 2003. Clinical and pathological study of an outbreak of obstructive urolithiasis in feedlot cattle in southern Brazil. Pesq. Vet. Bras. 23(2):61-64.
Louvandini H. \& Vitti D.M.S.S. 1994. Perda endógena de fósforo em ovinos com diferentes níveis do elemento na dieta. Pesq. Agropec. Bras. 29(1):145-149.

Mavangira V., Cornish J.M. \& Angelos J.A. 2010. Effect of ammonium chloride supplementation on urine $\mathrm{pH}$ and urinary fractional excretion of electrolytes in goats. J. Am. Vet. Med. Assoc. 237:1299-1304.

Maxie M.G. \& Newman S.J. 2007. The urinary system, p.425-522. In: Maxie M.G. (Ed.), Jubb, Kennedy and Palmer's Pathology of Domestic Animals. Vol.2. 5th ed. Saunders Elsevier, Philadelphia.

Navarre C.B. 2007. Urolithiasis in goats. Anais North American Veterinary Conference, Orlando, Florida [s.n], p.255-257. (Resumo)

Oliveira R.S.,Macedo J.T.A., Lents M.P., Silva R.M.M., Ferreira E.A., Pinheiro E.E.G., Costa J.N. \& Pedroso P.M.O. 2013. Urolitíase obstrutiva em touro Nelore no Recôncavo da Bahia. Acta Scientiae Veterinariae 41(Supl.1):14.

Paes P.R.O., Gonçalves R.C., Barioni G., Leme F.O.P., Melo M.M. \& Cruz M.L. 2012. O leucograma como indicador de estresse no desmame e no transporte rodoviário de bovinos da raça Nelore. Semina, Ciênc. Agrárias. 33(1):305-312.

Palviainen M., Raekallio M., Rajamäki M.M., Linden J. \& Vainio O. 2012. Kidney-derived proteins in urine as biomarkers of induced acute kidney injury in sheep. Vet. Journal 193:287-289.

Pires C.C., Silva L.F., Schlick F.E., Guerra D.P., Biscaino G. \& Carneiro R.M. 2000. Cria e terminação de cordeiros confinados. Ciência Rural 30(5):875-880.

Prado O.R., Monteiro A.L.G., Bastos G.M., Saab B.B., Quizini S.M.P., Pierobom C.C., Hentz F. \& Nomura T.M. 2013. Sistemas de alimentação e épocas de terminação sobre as medidas corporais pré-abate e da carcaça de cordeiros abatidos na região Centro-Sul do Paraná. Semina, Ciênc. Agrárias 34(6):3031-3042.

Rabinowitz, L., Gunther R.A., Shoji E.S., Freeland R.A. \& Avery E.H. 1973. Effects of high and low protein diets on sheep renal function and metabolism. Kidney Internancional 4:188-207.

Raekallio M.R., Saario-Paunio E.M.K., Rajamäki M.M., Sankari S.M., Palviainen M.J., Siven M.S., Peltoniemi S.M., Leinonen M., Honkavaara J.M. \& Vainio O.M. 2010. Early detection of ketoprofen-induced acute kidney injury in sheep as determined by evaluation of urinary enzyme activities. Am. J. Vet. Res. 71(10):1246-1252.

Riet-Correa F., Simões S.V.D. \& Vasconcelos J.S. 2008. Urolitíase em caprinos e ovinos. Pesq. Vet. Bras. 28:319-322.

Sacco S.R. \& Lopes R.S. 2011. Urolitíase: estudo comparativo em bovinos Guzerá oriundos de propriedades com e sem o problema. Pesq. Vet. Bras. 31(3):206-212.

Sahinduran S., Buyukoglu T., Gulay M.S. \& Tasci F. 2007. Increased water hardness and magnesium levels may increase occurrence of urolithiasis in cows from the Burdur region (Turkey). Vet. Res. Commun. 31:665-671.

Santarosa B.P., Goncalves R.C., Ferreira D.O.L., Barbosa C.C. \& Dias A. 2008. Perfil bioquímico renal em ovinos confinados tratados com cloreto de amônio e vitamina C. Anais XX Congresso de Iniciação Científica da Unesp, São José dos Campos, SP.

Silva P.C.A.R., Pitombo C.A., Caetano L.F.O., Lima A.G., Arêas V.S. \& Vargas Júnior L. 2008. Urolitíase em novilho Nelore não-castrado. Veterinária em Foco 5(2):131-136.

Sousa A.A.R., Nunes V.H.S., Oliveira R.A., Sousa A.A.S., Teixeira W.C. \& Coelho M.C.O.C. 2011. Urolitíase obstructiva em ovino. Acta Scientiae Veterinariae 39(2):970.

Stewart S.R., Emerick R.J. \& Pritchard R.H. 1991. Effects of dietary ammonium chloride and variations in calcium to phosphorus ratio on silica urolithiasis in sheep. J. Anim. Sci. 69:2225-2229.

Stratton-Phelps M. \& House J.K. 2004. Effect of a commercial anion dietary supplement on acid-base balance, urine volume, and urinary ion excretion in male goats fed oat or grass hay diets. Am. J. Vet. Res. 65:13911397.

Streeter R.N., Washburn K.E. \& McCauley C.T. 2002. Percutaneous tube cystostomy and vesicular irrigation for treatment of obstructive urolithiasis in a goat. J. Am. Vet. Med. Assoc. 221(4):546-549. 
Sun W-D., Zhang K-C., Wang J-Y. \& Wang X-L. 2010. The chemical composition and ultrastructure of uroliths in Boer goats. Vet. Journal 86:70-75.

Taffarel D.A., Costa P.B., Pozza M.S.S., Wobeto J.R. \& Munchen E.P. 2012. Correlação entre características físicas, $\mathrm{pH}$ e contagem bacteriana da urina de ovinos. Synergismus scientifica 7:3.
Van Metre D.C. \& Fubini S.L. 2006. Ovine and caprine urolithiasis: Another piece of the puzzle veterinary surgery. Vet. Surgery 35:413-416.

Zundt M., Macedo F.A.F., Martins E.N., Mexia A.A. \& Yamamoto S.M. 2002. Desempenho de cordeiros alimentados com diferentes níveis protéicos. Revta Bras. Zootec. 31(3):1307-1314. 